
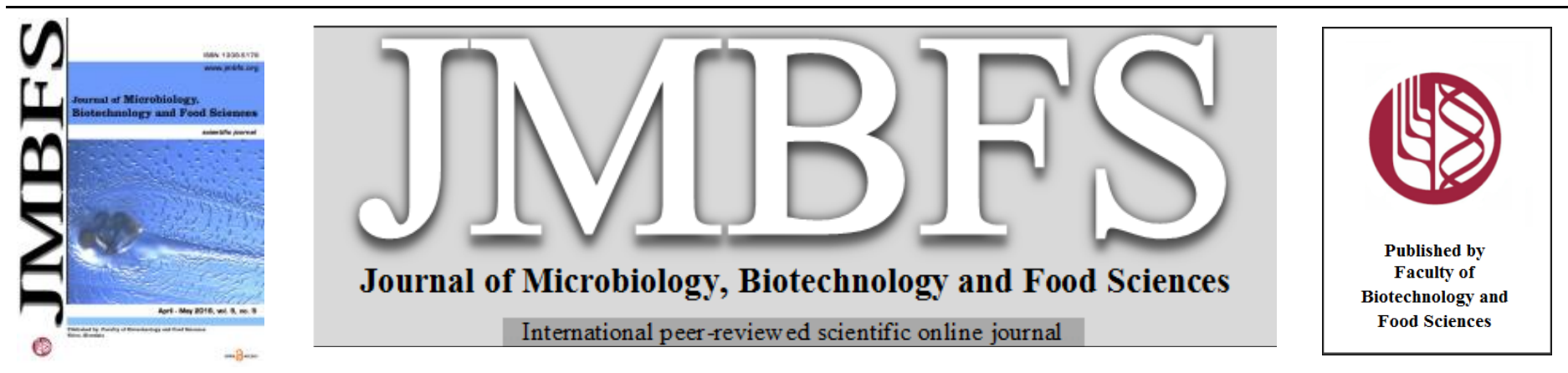

\title{
CLONING AND EXPRESSION MOST EXPECTED ANTIGENIC FRAGMENT OF BETA-TOXIN GENE FROM CLOSTRIDIUM PERFRINGENS TYPE B
}

\author{
Maryam Gholami ${ }^{1}$, Mohsen Fathi Najafi $*^{2}$, Mohammad Rabbani Khorasgani ${ }^{3}$,Behjat Majidi ${ }^{2}$
}

\begin{abstract}
$\operatorname{Address}(e s)$ :
${ }^{1}$ Department of Biotechnology, Faculty of advanced science and technologies, University of Isfahan, Hezarjarib St, 81746-73441, Isfahan, Iran. ${ }^{2}$ Department of Veterinary Research and Biotechnology, Razi Vaccine and Serum Research Institute, Ahmadabad St, Mashhad, Iran. ${ }^{3}$ Department of Biology, Faculty of Sciences, University of Isfahan, Hezarjarib St, 81746-73441, Isfahan, Iran.
\end{abstract}

*Corresponding author: m.najafi@mrazi.ac.ir

doi: 10.15414/jmbfs.2016.5.5.491-494

ARTICLE INFO

Received 26. 4. 2013

Revised 29. 5. 2015

Accepted 6. 1. 2016

Published 1. 4. 2016

Regular article

open $\odot$ access

\begin{abstract}
Clostridium perfringens type $\mathrm{B}$ and $\mathrm{C}$ is an important pathogen and produces Beta-toxin which are responsible necrotic enteritis in humans or livestock. The death in individuals with this disease are over $50 \%$. Vaccines against $C$. perfringens type $\mathrm{B}$ and $\mathrm{C}$ are currently manufactured using Beta-toxin produced by the virulent $C$. perfringens strain itself. To achieve the effective components for the creation of immunity at the first step used different primers in various location of Beta-toxin gene (cbp) by bioinformatics tools according to the secondary protein structure. After amplication of PCR products, one regions of Beta-toxin gene with high antigenicity was cloned into pTZ57RT and sub-cloned into the expression vector pET21a(+). The cloned vector was transformed into E. coli BL21 (DE3) and successfully expressed. Protein expression was confirmed by SDS-PAGE electrophoresis and western blotting. This recombinant peptide from most antigenic region of Beta-toxin gene can be suggested for antibody production and new peptide vaccine.
\end{abstract}

Keywords: Clostridium perfringens, Beta-toxin gene, Cloning

\section{INTRODUCTION}

Clostridia are ubiquitous and are commonly found in the environment, soil, decaying organic matter and a member of the gut flora in humans and animals (Cato et al., 1986). Clostridium perfringens is an anaerobic, Gram-positive, rodshaped, spore-forming bacterium that is one of most important pathogen of humans and livestock (Miclard et al., 2009; Rood and Cole, 1991).

$C$. perfringens produces numerous toxin which are responsible for severve diseases inclusing intestinal or foodborne in human and animals. This microorganism is classified into five toxintype (A, B, C, D and E) based on their ability to synthesize four major toxin, namely Alpha, Beta, Epsilon and Iota (Petit et al. 1999). C. perfringens type $B$ and $C$ isolates, which produce Beta-toxin (BT) that causes necrotic enteritis in human and domestic animal (Shatursky et al., 2000; Springer and Selbitz, 1999).

CBP is a lethal pathogenic factor of $C$. perfringens type B which aid in the lysis of HL-60 cells by forming cation-selective pores in the cell membrane (Nagahama et al., 2003). This function is necessary for both necrotizing enteritis and lethal enterotoxemia caused by $C$. perfringens (Nagahama et al., 2008; Sayeed et al., 2008). The gene for the BT has 1209 base pair with 336 amino acids in BT protein. The secreted toxin has similarities (based on $17 \%$ to $28 \%$ identity) to other toxins that are known to form pores in the plasma membranes of eukaryotic cells (Hunter et al., 1993). Therefore, the production of toxins in heterologous expression systems is viable altenative.

The efficiency of vaccines based $C$. perfringens recombinant Beta-toxin has been reported. The importance of the Beta-toxin in human and animal diseases has been demonstrated by immunization studies with Beta toxoid. In one study $\alpha-\beta$ fusion gene from $C$. perfringens type $\mathrm{C}$ was cloned and expressed in E. Coli (Bai et al., 2006). In this study the expressed $\alpha-\beta$ fusion protein can be used as the immunogens peptide for immunization. They constracted a recombinant epsilonbeta fusion protein for applying in vaccine production (Langroudi et al., 2011). In another study, $\alpha / \beta 2 / \beta 1$ trivalent fusion-toxin $(\mathrm{CPAB} 2 \mathrm{~B} 1)$ displayed increased immunogenicity relative to $\mathrm{CPA}$ and $\mathrm{CPB} 2 \mathrm{~B} 1$ alone. In other work, a vaccine based on Beta toxoid of $C$. perfringens type $\mathrm{C}$ produced and evaluated in E. Coli. The non-toxic recombinant Beta toxoid $(\mathrm{rBT})$ was innocuous for mice and induced beta antitoxin in rabbits (Milach et al., 2012).

The aim of this work is production a recombinant fragment of Beta-Toxin ( $\mathrm{r}-\mathrm{f}-$ $\mathrm{BT}$ ) from C. perfringenes type B in E. coli. Expected to use this recombinant protein for production of antibody against Beta-toxin of C. Perfringenes type B and futher applications.

\section{MATERIAL AND METHODS}

\section{DNA extraction}

Clostridium perfringens type B strain ATCC3626 prepared from Razi vaccine and serum research Institute. The cell was grown for 18 to $20 \mathrm{~h}$ at $37^{\circ} \mathrm{C}$ in TGY ( $2 \%$ Trypticase, $2 \%$ glucose, $0.5 \%$ yeast extract). Genomic DNA was extracted by standard method with phenol/chloroform/isoamyl alcohol method (Sambrook et al., 1989).

\section{Primer designing}

Since the aim of producing universal antibody for all antigenic components of Beta toxin $C$. perfringens therefore fragments of $\mathrm{cpb}$ were aligned and conserved gene sequences were selected. Multiple sequence alignments of 11 gene sequence of $C$. perfringens type B was performed using the CLUSTAL W2 program (include: B-CPB240, B-CPB213, B-CРB228, B-СРВ236, B-CPB220, BCPB214, B-B, B-cpb, B-C-b, B-CWB-CN-228, B-CN301), we designed universal primers from conserved regions. Different primers were designed in various location of C.perfringens cpb gene (GenBank Accession No. X83275.1) according to the secondary structure of protein (Table 1). Secondary structure of beta protein ( $\alpha$-helix and $\beta$-sheet regions) was obtained based on the amino acid sequence of Beta toxin using PSIPRED Bioinformatics, then primers were designed according to different situations and out of range of the $\alpha$-helix and $\beta$ sheet. Peptides outside the region of helix and loop regions are antigenic peptides. For confirmation of primer designing Immune Epitope Database (IEDB) was used. 
Table 1 Six oligonucleotide primers for PCR-synthesizing cpb gene.

\begin{tabular}{|c|c|c|c|}
\hline $\begin{array}{l}\text { Primer } \\
\text { name }\end{array}$ & Primer sequense & $\begin{array}{l}\text { Sequence } \\
\text { size }\end{array}$ & $\begin{array}{l}\text { Position } \\
\text { F-R }\end{array}$ \\
\hline $\begin{array}{l}\text { F1cbp } \\
\text { R1cbp }\end{array}$ & $\begin{array}{l}\text { aaa gag caa tgt tca ttt aac tta aca } \\
\text { tgt aga tga ttc agc ata ttc gct }\end{array}$ & 618 bp & $1-618$ \\
\hline $\begin{array}{l}\text { F2cbp } \\
\text { R2cbp }\end{array}$ & $\begin{array}{l}\text { act aat tct act gca att aat ttt ccg } \\
\text { gga ata gac ttg tcc tac cca gtt }\end{array}$ & 582 bp & 399-981 \\
\hline $\begin{array}{l}\text { F3cbp } \\
\text { R3cbp }\end{array}$ & $\begin{array}{l}\text { agc gaa tat get gaa tca tct aca } \\
\text { aat agc tgt tac ttt gtg agt aag cca }\end{array}$ & 474 bp & $\begin{array}{l}591- \\
1065\end{array}$ \\
\hline
\end{tabular}

Polymerase chain reaction (PCR)

The PCR was carried out in a final volume of $50 \mu 1$ containing $1 \mu \mathrm{g}$ template DNA samples which were extracted from the bacterial strains. The target fragment was amplified using PCR Master Mix (Bioneer). A total of 35 cycles was performed under the following conditions: $94^{\circ} \mathrm{C}$ for $5 \mathrm{~min}$, and 1 cycles at $94^{\circ} \mathrm{C}$ for $60 \mathrm{sec}, 56^{\circ} \mathrm{C}$ for $60 \mathrm{sec}, 72^{\circ} \mathrm{C}$ for $60 \mathrm{sec}$, then 1 cycles at $94^{\circ} \mathrm{C}$ for 60 sec, $54^{\circ} \mathrm{C}$ for $60 \mathrm{sec}, 72^{\circ} \mathrm{C}$ for $60 \mathrm{sec}$ and then 35 cycles at $94^{\circ} \mathrm{C}$ for $45 \mathrm{sec}, 52^{\circ} \mathrm{C}$ for $45 \mathrm{sec}, 72^{\circ} \mathrm{C}$ for $45 \mathrm{sec}$ with a final extension at $72^{\circ} \mathrm{C}$ for $10 \mathrm{~min}$. PCR products were detected by $1.0 \%$ agarose gel electrophoresis and photographed.

"Cloning and expression r-f-BT protein"

The PCR product of Beta-toxin gene (cbp) with one region of cbp with high antigenicity (based on antigen prediction bioinformatics tools) was selected and extracted from the gel using the DNA recovery kit (bioneer). The extracted fragment was ligated into vector PTZ57RT (InsTAclone ${ }^{\text {TM }}$ PCR Cloning Kit) according to manufacturers protocol. The recombinant plasmid was transformed into competent E. coli DH5 $\alpha$ and selected on LB agar plates containing Xgal/IPTG and ampicillin. The white clones with positive plasmid were selected and controled by PCR using its specific primers and M13 primers. Plasmid digestion was performed by EcoR 1 and Sal1 restriction endonuclease according to Fermentas protocol. After agarose electerophoresis, the EcoR1-cbp.f-Sal1 was purified and subcloned into pET21a(+) (Invitrogen) to generate the vector pET21a-cbp.f. This transformant was picked and used to inoculate LB medium. The recombinant vector pET-21a-cbp.f was transformed into E. coli BL21(DE3) and selected by agar plate containing ampicillin and confirmed by restriction enzyme mapping. BL21 cells transformed with the plasmids described above were grown in LB medium with $100 \mu \mathrm{g} / \mathrm{mL}$ ampicillin at $37^{\circ} \mathrm{C}$ to OD600 $=0.4 \sim 0.6$. At this time, the expression of the protein was induced by adding $0.1 \mathrm{mM}$ Isopropylthiobeta-galactoside (IPTG). The r-f-BT protein was purified (by instruction in www.thermo.com/pierce) and examined with SDS-PAGE and western blotting.

\section{RESULTS}

The aim of this project is to provide certain fragments of the Beta-toxin with high antigenicity and under epitope-focusing. First primers were designed based on the secondary structure with PSIPRED tool (Figure 1), then the results predicted antigenic regions of Beta-toxin by semi-empirical method showed that Beta-toxin has 9 antigenic regions which is shown in table 2. Thus region between 399-981 bp which has more than 5 antigenic regions of overlap with other fragments (Figure 2). Therefore this region was selected and tranformed.
A

[F1] AAAGAGCAATGTTCAITTAACTTAACAGATCATCTATATACA AAAGGAGGTTTTTTTATGAAGAAAAAATTTATTTCATTAGTTATA GTTAGTTCACTTTTAAACGGATGCCTATTATCACCAACTTTAGTG TATGCAAATGATATAGGTAAAACTACTACTATAACTAGAAATAA GACATCAGATGGCTATACTATAATTACACAAAATGATAAACAGA TAATATCATATCAATCTGTTGACTCTTCAAGTAAAAATGAAGAT GGTTTTACTGCATCTATAGATGCTAGATTTATCGATGATAAATAT TCATCTGAAATGACAACTTTAATAAACTTAACTGGATTTATGTCT TCAAAAAAAGAAGATGTTATAAAAAAATACAATTTGCATGATGT $T$ TI 2 ACTAATTCTACTGCAATTAATTTTCCGGTTAGATACTCGATT TCTATTTTAAATGAAAGTATTAATGAAAATGTAAAAATAGTTGA TAGTATTCCTAAAAATACAATTTCTCAAAAAACTGTATCCAATAC AATGGGATACAAAATAGGAGGTTCAATTGAAATAGAAGAAAAT AAACCTAAAGCTTCAATTGAA[F3]AGGGATATGCTGAATCATC TACAA[R1]TAGAATATGTCCAACCTGATTTTTCTACTATACAGAC AGATCATTCAACCTCTAAAGCTTCATGGGATACAAAATTTACAG AAACTACTCGTGGTAATTATAATTTAAAATCAAACAACCCTGTA TATGGAAATGAAATGTTTATGTACGGAAGATATACTAATGTTCC TGCAACTGAAAATATAATTCCAGATTATCAAATGTCAAAATTAA TAACAGGTGGTTTAAACCCTAATATGTCTGTAGTTCTAACTGCTC CTAATGGTACTGAAGAATCTATAATAAAAGTTAAAATGGAGCGT GAAAGAAACTGTTATTATCTTAATTGGAATGGTGCTAACTGGGT AGGACAAGTCTATTCC $[R 2]$ AGGCTAGCTTTTGATACCCCAAATGT AGATAGTCATATATTTACATTCAAAATAAATIGGCTTACTCACAA AGTAACAGCTATT[R3]TAGACTTTTATATTTGTACTAATATGAAT TTCAAATTAGTCCTTCGTATGTAATTTTAATACGGAAAGATGTAG CAAATGGTAATGAAGATGGTAGCATAACAAATGAAATTACTATA TCTAATAGGGGGAGCGTCCATAGCTGTCAACCTAAGAAGCCTCA CTTTCTATAATTAATTATTATA
B
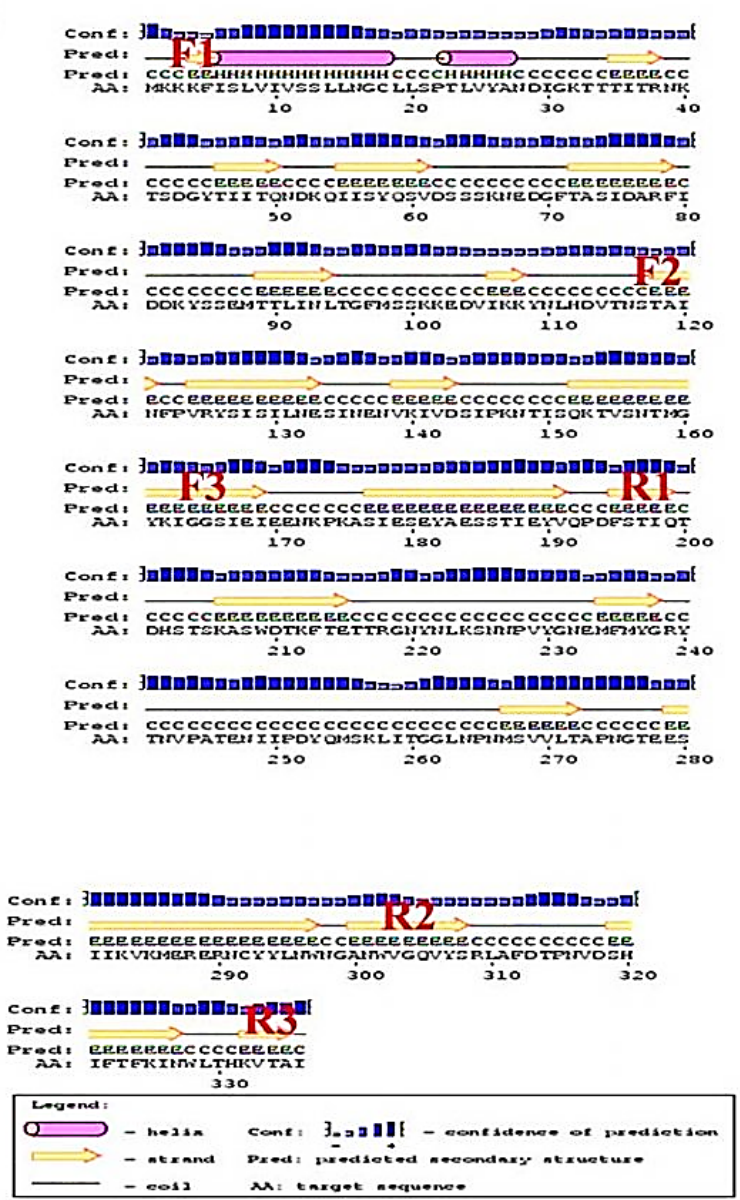

Figure 1 Bioinformatic tools for PCR Primer design A. Nucleotide sequence of Beta-toxin gene cpb from C. perfringens type B strain ATCC3626 and Suggested position for primers B. Primers was designed based on the secondary structure with PSIPRED tool. 
Table 2 Predicted peptides of Beta-toxin by semi-empirical method

\begin{tabular}{lllll}
\hline No. & $\begin{array}{l}\text { Start } \\
\text { Position }\end{array}$ & $\begin{array}{l}\text { End } \\
\text { Position }\end{array}$ & Peptide & $\begin{array}{l}\text { Peptide } \\
\text { Length }\end{array}$ \\
\hline 1 & 5 & 28 & $\begin{array}{l}\text { FISLVIVSSLLNGCLLSPTLVYA } \\
\text { N }\end{array}$ & 24 \\
\hline 2 & 55 & 63 & IISYQSVDS & 9 \\
\hline 3 & 103 & 114 & EDVIKKYNLHDV & 12 \\
\hline 4 & 120 & 132 & INFPVRYSISILN & 13 \\
\hline 5 & 138 & 145 & NVKIVDSI & 8 \\
\hline 6 & 188 & 196 & IEYVQPDFS & 9 \\
\hline 7 & 266 & 273 & NMSVVLTA & 8 \\
\hline 8 & 303 & 314 & VGQVYSRLAFDT & 12 \\
\hline 9 & 317 & 324 & VDSHIFTF & 8 \\
\hline
\end{tabular}

Kolaskar \& Tongaonkar Antigenicity

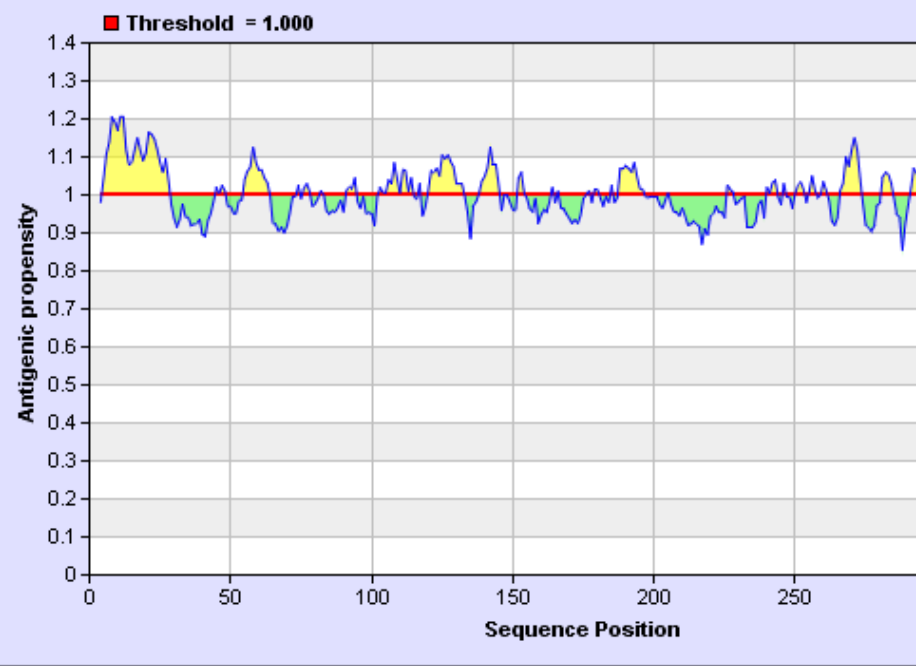

Figure 2 Semi-empirical method for prediction of antigenic regions of Beta-toxin C. perfringens.

\section{"Gene cloning and expression of r-f-BT gene" in E. coli BL21 (DE3)}

The r-f-BT gene from C. perfringens type B strain ATCC3626 was isolated from genomic DNA-extracted template by PCR amplification. The reaction yielded more products. Electrophoresis of PCR product confirmed the length of PCR fragment, which is shown in figure 3A. One of the fragments of Beta-toxin approximately $582 \mathrm{bp}$ with high antigenicity was ligated to the cloning vector pTZ5R/T with T4 DNA ligase. The cloning vector containing the r-f-BT gene was introduced into competent $\mathrm{E}$. coli $\mathrm{DH} 5 \alpha$ cells by $\mathrm{CaCl} 2$ transformation Transformed E. coli were grown at $37^{\circ} \mathrm{C}$ in medium containing X-gal/IPTG and ampicillin. The positive plasmids were identified via sequential digestion with EcoR I and Sal I and r-f-BT protective antigen gene about 582 bp was obtained (Figure 3B).

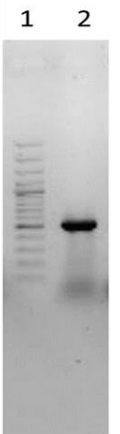

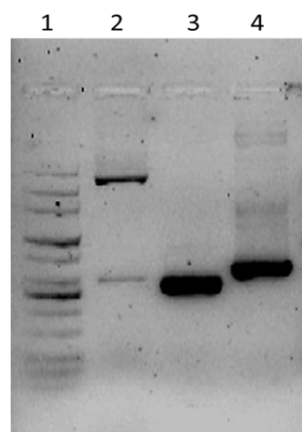

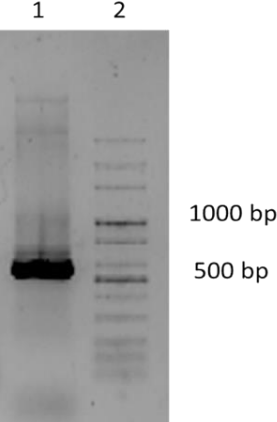

Figure 3 Agarose gel electrophoresis of r-f- $\beta$ gene was amplified by PCR A. Lane 1: DNA molecular marker (GeneRuler 100 bp Plus DNA Ladder 100 to 3000 bp), Lane 2: 582bp. In B. Lane 1: DNA molecular marker. lane 2: pTZ57CPB/EcoR1 + Sal I. Lane 3, 4: Colony PCR results with Primer F2R2 (582bp) and M13 universal primers (741bp). In C. Cloned fragment into PET21 (a+) was confirmed by specific Primer F2R2.

The recombinant plasmid pET-21a-cbp.f was transformed into E. coli BL21(DE3) and the recombinant strain BL21(DE3) was obtained. Then SDSPAGE and Brown band at the position of the reaction in western blotting confirmed the successful cloning and expression. The r-f-BT protein was produced in E. coli with an apparent molecular weight of $23 \mathrm{kD}$ was observed (Figure 4).

A

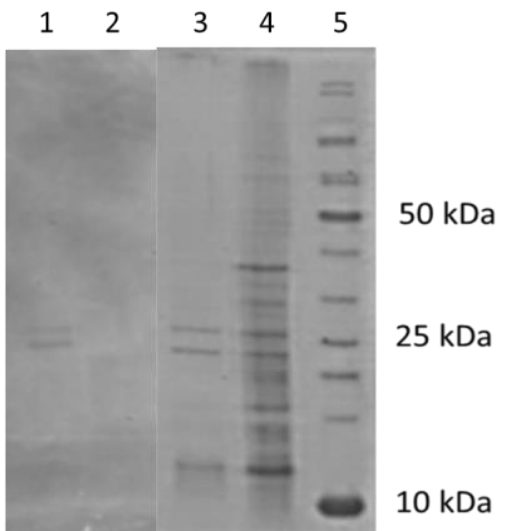

B

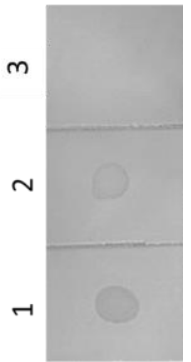

Figure 4 Characterization of r-f-BT producing in E. coli. A. Western blot and SDS-PAGE $12 \%$ analysis respectively, Lane 1: r-f-BT protein in reaction with native Beta-toxin antibodies. Lane 2: untransformed E. coli B121 (DE3) star extract (negative control). Lane 3: r-f-BT protein $23 \mathrm{kDa}$ purified from E. coli inclusion bodies, Lane 4: Supernatant from soluble fraction of recombinant E. coli. Lane 5: Fermetas unstained protein marker. B. The results of dot blot analysis using native Beta-toxin antibodies. Lane 1: r-f-BT protein, Lane 2: BT C. perfringens (positive control), Lane 3: negative control.

\section{DISCUSSION}

Beta-toxin is one of the lethal toxins produced by $C$. perfringens type $\mathrm{B}$ and $\mathrm{C}$ strains_Hunter et al., 1993_Beta-toxin of $C$. perfringens (CBP) type B is caused the principal disease such as lamb dysentery in Great Britain and South Africa (Niilo, 1980). Moreover, the toxoid vaccines majority of the commercial vaccines containing C. perfringens types B and C antigens, used in domesticated did not induce the minimum titers of $\mathrm{b}$ antitoxin, they are required to be tested for safety, residual toxicity and potency (Milach et al., 2012;Titball, 2009).

Vaccine based on recombinant Beta toxoid (rBT) produced and evaluated in Escherichia coli, the non-toxic $\mathrm{rBT}$ was innocuous for mice and induced $\mathrm{b}$ antitoxin in rabbits. In other study the Beta-toxin gene fused to the glutathione-Stransferase (GST) was cloned and expressed in E. coli. The purified fusion protein is not toxic in mice and raised rabbit antisera against it specifically neutralises the toxic effect BT of $\quad C$. perfringens type $\mathrm{C}$ culture filtrate in mice. Accordingly, the recombinant toxin proteins instead of their native toxins, are promising alternatives to the control of diseases caused by Clostridium perfringens (Milach et al., 2012; Steinpórsdótti et al.,2006). Other result suggested that recombinant toxoids are potential vaccine candidates against Clostridial toxins (Zeng et al., 2011).

Due to the strong toxicity of Beta-toxin, we decided to evaluate a recombinant form of the toxin (rec- $\beta$ ) as a potential antigenic toxoid for production of a recombinant vaccine against $\mathrm{C}$. perfringenes in future studies, after immunogenicity assay. As regards, the technology of recombinant protein antigens for immunization goes to identification main epitopes of protein antigens. Therefore antibody production is more successful with segments which contain epitope-focused antigens. The aim of this project is cloning a small fragment of the Beta-toxin with high antigenicity and epitope-focusing. First we designed primers according to the sequence and secondary structure of proteins that after protein structures are preserved; Beta-toxin has been shown more $\beta$ sheet than $\alpha$-helix by secondary structure prediction. According to previous research, most pore-forming protein toxins have extensive $\beta$-sheet in their structure which can create suitable antigenic effect (Parker and Feil, 2005). The variable regions were located in the external loop structures, while the predicted $\beta$-strands were formed by conserved sequences. The primers designing was done in external loop position. Epitope analysis plays an important role in the development of effective vaccine and diagnostic tools for different infection. In one study using different bioinformatics tools, one of the B cell epitopes of epsilon toxin comprising the region (Etx40-62) was identified. The rLTB.Etx4062 fusion protein thus can be evaluated as a potential vaccine candidate against C. perfringens (Kaushik et al., 2013).

In the present study we describes the successful isolation and cloning f-BT gene from strain of $C$. perfringens. We constructed a r-f-BT protein from $C$. perfringens type B. Ultimately western blot of r-f-BT protein showed that the antibodies specifically recognize antigen which it is attached. In summary, our findings demonstrate that r-f-BT of $C$. perfringens was capable of reacting with native Beta-toxin antibodies. The recombinant toxins with epitope-focused also be used to produce monoclonal antibody for immunoassay or possible therapy.

\section{CONCLUSION}


Herein, we reported that a r-f-BT of $C$. perfringens type B has been cloned and expressed in E. coli BL21, the achievement of this study was the production of $\mathrm{r}$ f-BT with high antigenicity. These recombinant toxin (r-f-BT) proteins can replace the natural protein and can be used immunological detection of specific antibodies against the Beta toxin and vaccine research. These approaches were successful in maintaining the antigenicity of the epitope using bioinformatics tools, significantly minimize the time and efforts in generating recombinant protein with high antigenicity.

Acknowledgments: We acknowledge and also appreciate the financial support provided by Razi Vaccine and Serum Research in Mashhad and University of Isfahan for this research.

\section{REFERENCES}

Bai, J. N., Zhang, Y., \& Zhao, B. H. (2006). Cloning of $\alpha-\beta$ fusion gene from Clostridium perfringens and its expression. World journal of gastroenterology: WJG, 12(8), 1229. http://dx.doi.org/10.3748/wjg.v12.i8.1229

Cato, E. P., George, W. L., \& Finegold, S. M. (1986). Genus Clostridium, Bergey's Manual of Systematic Bacteriology, vol. 2.

Hunter, S. E., Brown, J. E., Oyston, P. C., Sakurai, J., \& Titball, R. W. (1993) Molecular genetic analysis of beta-toxin of Clostridium perfringens reveals sequence homology with alpha-toxin, gamma-toxin, and leukocidin of Staphylococcus aureus. Infection and immunity, 61(9), 3958-3965.

Kaushik, H., Deshmukh, S., Mathur, D. D., Tiwari, A., \& Garg, L. C. (2013). Recombinant expression of in silico identified Bcell epitope of epsilon toxin of Clostridium perfringens in translational fusion with a carrier protein.Bioinformation, 9(12), 617.

http://dx.doi.org/10.6026/97320630009617

Langroudi, R. P., Pour, K. A., Shamsara, M., Jabbari, A. R., Habibi, G. R. Goudarzi, H., \& Ghorashi, S. A. (2011). Fusion of Clostridium perfringens type $\mathrm{D}$ and $\mathrm{B}$ epsilon and beta toxin genes and it's cloning in E. coli.Archives of Razi Institute, 66(1), 1-10.

Miclard, J., Jäggi, M., Sutter, E., Wyder, M., Grabscheid, B., \& Posthaus, H. (2009). Clostridium perfringens beta-toxin targets endothelial cells in necrotizing enteritis in piglets. Veterinary microbiology, 137(3), 320-325. http://dx.doi.org/10.1016/j.vetmic.2009.01.025

Milach, A., de los Santos, J. R. G., Turnes, C. G., Moreira, Â. N., de Assis, R. A., Salvarani, F. M., ... \& Conceição, F. R. (2012). Production and characterization of Clostridium perfringens recombinant $\beta$ toxoid. Anaerobe,18(3), 363-365. http://dx.doi.org/10.1016/j.anaerobe.2012.01.004

Nagahama, M., Kihara, A., Kintoh, H., Oda, M., \& Sakurai, J. (2008). Involvement of tumour necrosis factor- $\alpha$ in Clostridium perfringens $\beta$-toxininduced plasma extravasation in mice. British journal of pharmacology,153(6), 1296-1302. http://dx.doi.org/10.1038/bjp.2008.9

Nagahama, M., Morimitsu, S., Kihara, A., Akita, M., Setsu, K., \& Sakurai, J. (2003). Involvement of tachykinin receptors in Clostridium perfringens betatoxin-induced plasma extravasation. British journal of pharmacology, 138(1), 23 30.

http://dx.doi.org/10.1038/sj.bjp.0705022

Niilo, L. (1980). Clostridium perfringens in animal disease: a review of curren knowledge. The Canadian Veterinary Journal, 21(5), 141.

Parker, M. W., \& Feil, S. C. (2005). Pore-forming protein toxins: from structure to function. Progress in biophysics and molecular biology, 88(1), 91-142. http://dx.doi.org/10.1016/j.pbiomolbio.2004.01.009

Petit, L., Gibert, M., \& Popoff, M. R. (1999). Clostridium perfringens: toxinotype and genotype. Trends in microbiology, 7(3), 104-110.

http://dx.doi.org/10.1016/s0966-842x(98)01430-9

Rood, J. I., \& Cole, S. T. (1991). Molecular genetics and pathogenesis of Clostridium perfringens. Microbiological reviews, 55(4), 621-648.

Sambrook, J., Fritsch, E. F., \& Maniatis, T. (1989). Molecular cloning (Vol. 2, pp. 14-9). New York: Cold spring harbor laboratory press.

Sayeed, S., Uzal, F. A., Fisher, D. J., Saputo, J., Vidal, J. E., Chen, Y., ... \& McClane, B. A. (2008). Beta toxin is essential for the intestinal virulence of Clostridium perfringens type $\mathrm{C}$ disease isolate $\mathrm{CN} 3685$ in a rabbit ileal loop model. Molecular microbiology, 67(1), 15-30.

http://dx.doi.org/10.1111/j.1365-2958.2007.06007.x

Shatursky, O., Bayles, R., Rogers, M., Jost, B. H., Songer, J. G., \& Tweten, R. K. (2000). Clostridium perfringens beta-toxin forms potential-dependent, cationselective channels in lipid bilayers. Infection and immunity, 68(10), 5546-5551. http://dx.doi.org/10.1128/iai.68.10.5546-5551.2000

Springer, S., \& Selbitz, H. J. (1999). The control of necrotic enteritis in sucking piglets by means of a Clostridium perfringens toxoid vaccine. FEMS

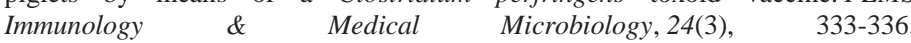
http://dx.doi.org/10.1111/j.1574-695x.1999.tb01302.x

Steinpórsdótti, V., Fridriksdóttir, V., \& Gunnarsson, E. (2006). Expression and purification of Clostridium perfringens beta-toxin glutathione S-transferase fusion protein. FEMS microbiology letters, 130(2-3), 273-278.

http://dx.doi.org/10.1016/0378-1097(95)00218-t
Titball, R. W. (2009). Clostridium perfringens vaccines. Vaccine, 27, D44-D47. http://dx.doi.org/10.1016/j.vaccine.2009.07.047

Zeng, J., Deng, G., Wang, J., Zhou, J., Liu, X., Xie, Q., \& Wang, Y. (2011) Potential protective immunogenicity of recombinant Clostridium perfringens $\alpha$ $\beta 2-\beta 1$ fusion toxin in mice, sows and cows. Vaccine, 29(33), 5459-5466. http://dx.doi.org/10.1016/j.vaccine.2011.05.059 